\title{
Problems Emerging in Online Education During Lockdown Period of COVID-19 Pandemic
}

\author{
Yixin Qian \\ School of Education, University of Pittsburgh, 4200 Fifth Ave, Pittsburgh, PA 15260 \\ qianyixin_2020@163.com
}

\begin{abstract}
During the lockdown period of COVID-19, many Chinese traditional educational institutions start to shift their pedagogical methods from face to face education to online tutoring. In this dramatic transformation, the application of technology leads to some problems that are awaiting to be tackled. This study mainly focuses on emerging problems from students' poor outcomes of their language learning online, students' and parents' attitude toward digital education to challenges teachers are facing. Suggestions and recommendations will be provided to promote the effectiveness of online language teaching and learning.
\end{abstract}

Keywords: Online education, Language education, Lockdown period, COVID-19.

\section{Introduction}

The movement from traditional teaching to modern technology-supported education appears to be inexorable in the era of 21st century. Until COVID-19 outbreak, many educational institutions, schools and universities used online classes only as a facilitator in education [1]. However, after the spread of this deadly virus, many organizations and governments start to provide instructional materials and resources to teachers and practitioners for online teaching [2]. Both formal and informal education has been heavily affected, shifting traditional pedagogical methods to modern approaches of online teaching and learning [3]. Online courses become compulsory than optional for teachers and learners.

Given the continuous worsening COVID-19 situation, this study examines problems and issues emerging within the online language teaching and learning context during the lockdown period in Yangzhou, a city located in mainland China. In particular, this study focuses on investigating the efficiency of online language classes and students' and parents' attitude toward taking classes online as an emergency protocol implemented in one educational institution. Many such educational institutions previously relied on blended learning, a combination of face-to-face classroom practice with technology-mediated distance education, but as the pandemic sets in, educators, language learners, and their families are forced to shift into digital education [4]. In this process, loads of problems turn up. Findings in this study spotlight some problems emerging when educational institutions attempt to revamp their education and are hopefully conducive to educators and administrators who are relatively unfamiliar with online teaching and expect some practical suggestions for high-quality online class delivery and effective school-home connection.

\section{Literature Review}

Though technology has played an indispensable role in a modern class where multimedia teachings tools are in part used by teachers, how promising online education is remains highly debatable. One voice is that technology serves as an essential tool to facilitate both teaching and learning [5]. First to teachers, for example, computer-based teaching helps teacher be accessible to more teaching materials and sufficiently prepared for classes [6]. Since there is no geological limitations, more authentic materials such as news, stories, and songs in target language are available and used by teachers to help students achieve their academic goals [7]-[8]. Teaching becomes interesting and student outcomes are positive in that a myriad of options are provided by technology [9]. Technology likewise has facilitated learner's learning [5]. Learning becomes more appealing to students for technology can precisely figure out what target students are interested in and provide differentiated instructions [10]. Especially to language learners, they are able to learn new words online, ask for professional help, become globalized, and hone their academic skills through learning online [11].

However, doubt is also cast on online teaching and learning. Malfunction in technology such as downloading failure, installation problems, unstable internet connectivity, and lack of digital devices is found impeding the success of online learning $[12,13]$. A great amount of time is required in a delivery of an online class while it may cause imbalance of time allocation between teaching practice and technical operation [12]. Online and distance education may be restricted to students who are equipped with certain skills, which leads to educational inequality [14]. Due to the convenience brought by the usage of advanced inputting methods, students don't know how to correctly spell words [7]. Lack of community and difficulties in understanding instructional goals affect learning efficiency [15]. In one research, scholars review a great number of literature by using sociological, educational, psychological electronic databases, and systems such as Google scholar and Google [16]. After excluding studies of poor quality, they find that there is little evidence so far strongly proving the effectiveness of the use of technology in education and they further advocate that large-scale studies need to be conducted before any conclusion is confirmatively drawn.

However, because of the spread of COVID-19, online teaching and learning becomes a necessity. A severe challenge faced by all educational institutions is to rethink and redesign their educational mode. Thus, objectives of this study are: 
To spot some problems emerging in online teaching and learning as a traditional education institution tries to shift face-to-face teaching mode into online tutoring;

To analyze main reasons for the poor outcome of online classes and give some suggestions and recommendations for educators and administrators in the time of crisis

\section{Methods}

\subsection{Setting and Participants}

The study focuses on a language program in an educational institution in Yangzhou. This program aimed to improve students' English proficiency levels and get students prepared for their future study in English speaking countries. Every course package in this program included four subjects, namely reading, listening, writing, and speaking, each of which was taught by one different English instructor for sixteen hours. One subject had eight classes each of which lasted for two hours with a ten-minute break after students had a one-hour class. Every student took classes twice a week. Because I was one of the instructors, teaching speaking part, the observation for this study only took place when students were taking speaking classes. All students took online classes at home via a system called Cloud Class. The main functions of this system allow teachers to display PowerPoint, play video or audio clips, play games, partly control students' screens, and perform other teaching practices. All teaching materials used for every student were the same and adhered to a predesigned curriculum.

The participants included fifteen students and their parents. Those students were from seven schools whose mean age was 18. Two of them were 16 years old, currently studying in the same junior high school and four of them were about 20 years old, studying in four different universities. The rest of the students were from two senior high schools and their age ranged from 17 to 19 . Among all fifteen students, six of them were in one class and the rest nine students were taught individually. All the students were required to take a pre-task and their speaking proficiency levels were assessed based on their performances demonstrated in this task. Those students reached intermediate high to advanced low levels of language proficiency, meaning they could "create with language" and respond to questions with ease in some informal settings they were familiar with but had difficulties when required to handle a more complex academic topic [17].

\subsection{Data Collection and Analysis}

The study was conducted using close observation in order to document students' performances for each class and collecting descriptive feedback from a written interview given to both students and parents about online learning experience after the last class. Through observation, students' completion of assignment, academic performances, and their engagement in class were recorded. Their academic performances were assessed according to ACTFL Assessment Criteria for speaking basically from four aspects: functions, context, accuracy, and text type [17]. After the last class, each student was assigned a post-task to measure their proficiency levels after taking online classes. Tasks in both tests were different but equally difficult. After the post-test, an online written interview was given to students with their parents. Students and parents were asked some questions with prompting questions when their answers were not detailed or informative. Three basic questions were: a. "Do you prefer an online class? Why or why not?"; b. "Have you spent more time and effort taking online classes?"; c. "Do you have any concerns about online language learning?". To set the first question is to see whether learners were wont to take classes online or any inconvenience was perceived. The second question is designed for obtaining information about the efficiency of online learning. The last question may help us improve our online teaching in the future. Because educational service was usually rated highly by parents and students in this educational institution based on previous feedback collection experience for various reasons, quantitative analysis could not objectively reflect real situations. Rather, descriptive statistics and observation was crucial in this study.

\section{Findings}

\subsection{Students' Academic Performances}

Five out of the fifteen students showed slight improvement in their speaking in a post-test. All the five students reached an intermediate high level when they took the pre-task. In the post-task, those students demonstrated a better control of their language use. For example, one student, in terms of function, context, and text type, could organize simple or discrete sentences to answer school-related or home-related questions. In terms of accuracy, his answers were usually short and brief, containing loads of grammatical errors, limited appropriateness of vocabulary, and occasionally meaningless information. After he took online classes, his discourse was of passage length with fewer grammatical errors, more proper word choice, and more self-correction when he spoke. Within the context area, he could handle somewhat more complicated academic topics. In terms of accuracy, text type, and context, another student was used to repetition and strings of sentences when he answered simple questions most of which he was familiar with. His repetition was greatly reduced after he took classes. He could successfully handle some formal settings and answer in longer sentences sometimes even with clauses. Obvious improvement, however, was not observed in the rest of the students. Especially to those students who had already reached advanced level, their academic performance remained the same except that they were more familiar with some academic topics discussed in class. Overall, taking class online in this study more benefits students with lower academic levels.

\subsection{Students' Engagement in Class}

First, this study found that most students started to lose their attention to learning after approximately forty minutes to one hour in class. In the second half of the class, students' attention was drawn back when they were invited to play interactive games online, but they demonstrated poor focus shortly after they played the games. Poor concentration was detected in a few students after only 20 minutes in class. Second, less interaction was observed in an online class. Some students even muted themselves when asked to participate in a group discussion. Third, some students, when 
taking classes online, didn't behave properly. For example, one student took classes while lying on the bed in her pajamas.

One function of the Cloud Class System allows teachers to remotely lock students' screens while they are taking classes. This indicates a possibility that students may be distracted by other social media without teachers being aware of the situation is potentially existing. In fact, some students confessed if the teacher had not locked their screens, they would have occasionally returned to social media or games. When this happens in a real class, a shift from knowledge intake to interaction between learners and instructors is expected to improve this situation. Cloud Classroom system allows teachers to play games to energize a class. Yet it is disappointing to notice that students' attention dropped after they became familiar with those games. Some students even showed no interest in those activities. As is suggested in the finding, a considerable number of students were insufficiently attentive when they were taking classes online even after an interactive activity.

\subsection{Assignment Completion After Class}

After each class, two to three tasks were assigned to students, normally taking students 40 minutes to finish. Just four students, however, would submit their assignment before deadline. Nine students finished $60 \%$ to $80 \%$ of their assignments while two students never submitted their assignments even after parents were informed about the situation. When students were required to give a reason why they didn't finish their assignment on time, some students explained that because they felt less peer pressure, they were internally less motivated to finish their assignments. As a result of taking classes online-no classmates or teachers could be physically around those students-the endogenous motivation impelling some students to achieve a goal consequently started to decrease and finally gave way to sluggishness and procrastination.

\subsection{Students' and Parents' Attitude Toward Online Learning}

In the online written interview after the last class, most learners and parents preferred learning in a more traditional mode for when they were sitting in a traditional classroom, they could be more attentive to lecture and more involved in interpersonal activities. One student added that she felt she was cared when she received direct eye contacts or a tacit simile from other people and that her confidence was boosted by such silent interpersonal "communication".

When students and parents were asked whether they needed to spend more time or effort taking online classes, they showed a very mixed attitude. Some complained that they were troubled by weak internet connection while others were glad that commuting time was greatly saved. In general, parents and students who were more computer literate showed a more temperate attitude towards online learning. Contrarily, students and parents who were less "computer savvy" were more likely to harbor negative views toward this new learning mode. For example, one student told me she had spent 20 minutes just trying to log in her account to get her assignments done. Another student complained that after submitting his assignments, he noticed one of his answers was not recorded by his built-in microphone.

When parents and students were asked whether they had some worries about online classes, parents did more or less express their concerns that when students were taking classes online, they didn't know how to help them. Through observation, three parents indeed appeared in the screen and tried to offer some help when students were taking classes. Two of them came into rooms to ask students whether they would need any help, the behavior of which undoubtedly distracted students from their speaking tasks. One parent audited the entire class without any permission and provided extra pedagogical instructions during the class, which confused this student and seriously affected learning efficiency because rationales behind the teaching design had to be explained to that parent and previous teaching instructions needed to be repeated before the class could move on. However, parents' behaviors implicitly conveyed their concerns to educators.

\section{Discussion}

Through the one-month observation of online English speaking classes, some findings in this study help us keep alert eyes on online teaching and learning. But what is more important is to take a look at the reasons behind the phenomena in order to further our understanding of online teaching and learning and optimize education for both teachers and language learners.

\subsection{Less Effective Classroom Management}

Through the observation, it provokes one perplexing question: why online classroom management failed? First of all, students are more likely to be distracted in a home setting. For example, one student said his cat was ambling around him while he was taking class. This would definitely distract his attention from lecture. Second, zero physical contacts between real people leads to an absent sense of presence. As a result, students feel less stress and may show signs of poor concentration. For example, one student shared his online learning experience. In his description, he was not in a state of nervous excitement in class. Then he cracked a joke, saying that "when I am taking online classes, it is like playing a video game where you can see virtual characters talking to you." A lack of sense of presence relieves the stress a student should take. However, the relationship between stress and productivity is long believed can be graphed as an inverted U-shaped curve, suggesting that the optimal performance is exhibited under stress in appropriate amounts [18]. When stress intensity is low, students fail to maximize their potential. Third, games designed in this system are not suitable for the target age group. The finding suggests that using a system even with gamified elements may lose students' attention. That is probably because students become bored after being repeatedly engaged in the same simple games not challenging to them. Forth, staying put for a long time makes people feel exhausted. Some students asked for rest during class time because they felt tired. After class, some students said that they were extremely spent. Indeed, frequently remaining sedentary can lead to fatigue.

From a teacher's perspective, in a traditional class, a teacher 
can keenly perceive students' inattention to the class by reading students' facial expressions and so forth, but when teachers are teaching online, noticing students' poor focusing on class becomes more difficult. For example, one student later admitted that he put one digital device on a holder below his webcam. Because his eyes were seemingly fixed on the screen, he was not caught playing games on that device during class. Further, a teacher may apply multiple physically interactive methods to energize a face-to-face class, but it may be more challenging to try active learning activities especially when there is a considerable number of students involved in an online class. For example, in one class six students took, all of them were divided into two groups to do group discussion. When students were speaking simultaneously, distinguishing voices from different students and providing immediate feedback through the discussion to facilitate language learning would be difficult due to technical defects. While in a traditional class, this problem can be tackled with little effort - standing next to target students and walking around in the classroom. Apart from less effective interaction activities, internet issues such as a weak internet connection or frequent network lag also bothered both students and teachers. Overall, we have an urgent need to improve current technologies and have a well-tested class design, thereby avoiding failure of classroom management.

\subsection{Improper Parental Involvement}

Through observation, some parents were involved in class. When asked about the motivation, parents said they tried to give instructions or help to their children because they thought a little help should be offered. Only by offering what they thought was necessary could they think they were responsible and caring as parents. What they didn't realize was that the help they supplied didn't essentially improve students' academic achievement for they failed to accurately spot students' problems and develop any effective study plan. Contrarily, class time was wasted and less positive effects of teaching was foreseen as parents didn't get enduring and deep training about language teaching before. This type of parental interference goes too far.

Even though the parental interference observed at different times during the classes is improper and unnecessary, the occurrence of inopportune parental involvement was caused largely because parents didn't know appropriate approaches to get themselves involved in education when students studied all day at home. When we drill down to the deep, this undue interference of online language learning results from parents' concerns which are not totally groundless. First, parents have doubts about ultimate academic achievement of online learning because this mode of teaching is totally new to them. Unfortunately, there is little evidence heretofore to confirm that online learning is beneficial for students [16]. Therefore, rightful concerns from parents are hardly eliminated so far. Additionally, in this study most parents were relatively ill-equipped to offer any academic or technical help to students by reason of their comparatively low academic levels and lack of computer literacy. Most parents preferred assignments that were more checkable to them. One obstacle parents met when they tried to know students' current learning status with their own eyes rather than feedback provided by schools sometime later was that they didn't know how to ensure students had fully done online tasks or to check the quality of their assignments with their deficient knowledge of technology. This sense of powerlessness contributes to parents' concerns about online learning.

\subsection{No Apparent Advantages of Online Learning}

Findings in this study suggest that students with lower academic levels gained more benefits from online learning. One student said that when she saw a picture of a target word, this word was anchored in her mind. Admittedly, a video played or a picture shown will greatly avail a student of a newly-learned word if the student is a visual learner [19]. A piece of English music will assist an aural learner alike [19]. However, findings also reveal a fact that many others students didn't gain apparent improvement after taking online classes. To explain the phenomenon, we should first examine students' learning content. As students learn in depth, advanced students are more likely to be exposed to abstract concepts expressed in scholastic terminologies. It is not uncommon that a terminology is coined by scholars as an ad hoc tool in an academic context. No pictures or video clips can fully clarify an obscure idea or an abstruse theory when learners study a subject in a second language. In this case, immersion is often used as a pedagogical approach to teach students both regular school subjects and the second language while online learning falls well short of our expectation [20]. For example, when the term ammonia was mentioned in a speaking class, one chemical property of ammonia is its distinct pungent odor. However, the memory of this unpleasant smell could not be precisely formed only by words or pictures.

Second, what a teacher can display is limited in a class. We can not expect to visualize every knowledge point in an informative textbook. But when advanced students are required to get accustomed to fast-paced learning successfully to pass some highly-demanded exams within a given period of time, students have to shift back to their textbooks for preparation to save time. In this study, most students memorized important knowledge points primarily by rote learning. To students with needs of passing an impending test, online learning has no significant advantages when compared with the traditional learning mode because extra browsing for information about only one knowledge point is time-consuming. For example, one student had registered a speaking test before she took these online classes. She had only two months to prepare for this test. Her problem was that she didn't have a large vocabulary so her solution was to buy a vocabulary book and crammed for her test. Theoretically, a picture might help her better understand a new word, but she had no time to do this in reality.

\subsection{Teachers' Inexperience of Knowledge Delivery Online}

Teaching online is still a new issue in many educational institutions in China. Before coronavirus pandemic, many institutions preferred traditional teaching in Chinese educational market. After this formidable outbreak of coronavirus in many cities, the majority of institutions are forced to transform traditional offline teaching to online tutoring. This dramatic transformation results in less professional teacher training because no one in such an 
institution has rich experience or empirical data to support further teacher training. For example, in one famous educational institution in China, their teacher training requires pre-service and new teachers to participate in a one-week training where those teachers observe and discuss some demo lessons taught online, practice in study groups, write and submit learning reports, and finally are scored by their tutors and given feedback, but this one-week training is neither systematic nor sufficient and no theoretical evidence robustly proves the efficiency of those teaching methods. In this one-week training, the organizer identifies several topics that are not co-related about difficulties senior teachers mutually encountered according to their personal work experience; more topics are nonetheless awaiting to be explored. After this one-week training, no other related training is further offered periodically and no other people organize similar training again. Even in such a well-organized educational institution, online teaching training is not in depth and continuous, let alone other institutions without an elaborate teaching plan or scientific management. Generally, many teachers solve problems about online teaching independently. When a teacher is not familiar with a new system or unable to control a class effectively, very little assist is delivered by colleagues because they are also initially ill-trained.

\subsection{Behavioral and Psychological Changes of Online Learning}

Taking a language class with classmates in a real classroom serves a dual function: enhancing language learning and regulating social behaviors in a nonresident school setting. Through observation, however, a few students muted themselves when they were encouraged to employ the new language in a group discussion. "When I take classes online, I feel less peer pressure. But if I keep silent in a real classroom setting, I will feel awkward because I can perceive eye contact from others", the student, muting himself online, explained. Thus, online learning rendered less peer-to-peer connection. In another condition where students were muted in order to enhance lecture effectiveness, no opportunities were given to students for peer scaffolding or learning. According to Vygotsky, much important learning actually occurs when social interaction happens through a cooperative or collaborative dialogue between an instructor and a students or among students [21]. Further, that students take a class in a classroom physically being with classmates is not only to acquire a language but also to learn how to establish and solidify a long-term cooperative relationship with others and how to behave appropriately to meet social needs and obligations. In a traditional class, students subconsciously or intentionally behave more properly, desiring to build a more socially acceptable image of themselves in order to avoid becoming unwelcome people. However, when students took online classes, some of them are nonetheless more likely to act in such an impolite manner as lying on the bed or wearing pajamas because an online class provided students with great flexibility - they had an environmental condition and less peer pressure to behave improperly.

On a psychological level, what we wear affects how we perceive ourselves according to the theory of enclothed cognition [22]. Causal clothing students wear when studying at home all day doesn't help foster a focused mindset. For example, one student who was always in her pajamas said that she felt sleepy and dozy even in the day time. In a sharp contrast with this student wearing casually, another student who had to stay in his dorm because of the pandemic was used to wearing a school uniform, giving others a sense of verve and vitality. Indeed, keeping formal wear in public eye helps students get into a more productive learning mode.

\section{Recommendations for Successful Online Teaching and Learning}

In order to improve our online teaching practice in the future and help learners better achieve their goals, there are some suggestions we may consider:

1) Technology experts should design a system that may help teachers control the class more effectively. This system should be characterized by following features:

a. Multiple games catering to target age groups can be incorporated in to energize the class;

b. PowerPoint, video or audio clips, and other multimedia can be properly used;

c. Behaviors such as cheating, being distracted, passively participating in a group discussion, plagiarizing, and other unacceptable academic manners can be successfully recognized and teachers are informed in time;

d. A user-friendly platform is built for social networking between teachers and students, students and students, teachers and parents, and even schools and schools;

e. Assignments are more checkable to parents and teachers and a more reliable rating system is applied.

2) A booklet with clear illustrations or an instruction video is produced to offer parents technical support. With regard to parents' reasonable concerns about online learning, teachers can create a to-do list with clear steps for both parents and students. In the to-do list, students are clear about the requirements of their assignments and how their performances will be valued while the professional criteria are expressed in a simplified language parents can understand. More importantly, parents are provided with suggestions about how to help students consolidate knowledge through practice at home. Practical steps of educational guidance are clearly but briefly listed for parents.

3) Class rules and behavioral standards are set beforehand and strictly implemented through teaching. If a student behaves badly, there will be a well-established punishment mechanism. For example, when a rule that requires all students to wear a uniform or keep formal wear is violated, digital feedback system will send a message to inform parents. Alternatively, students will lose some credits if caught by the system.

4. Teachers should: a. record problems they meet and provide solutions if they have any; b. have weekly or monthly seminars to cover those problems, gather solutions, test them, and list those solutions into a pamphlet for future use; c. share experience with other teachers and, if possible, spot new trend in digital education; d. optimize current teaching plans and 
consider how to effectively integrate technology in a class with theoretical support; e. get enough support and technical assistance from schools.

\section{Conclusion}

This study focuses on several emerging issues raging from students' and parents' perception of online education, the effectiveness of taking online classes amidst COVID-19 pandemic to teachers' challenges. Although we can swiftly turn to online tutoring with the help of modern technology, problems, visible or invisible, still exist. It is undeniable that technology becomes an inalienable part of education in response to the COVID-19 catastrophe, but how technology will navigate our way to the best education in the future is still uncertain. The most important task we are currently facing is to find the best possible solutions to tackle problems we have encountered when teaching or learning online. More research should be conducted to detect profound effects of online education. As we may believe, learning a language is "a perennial undertaking" [23]. Another enduring task is how to maximize potential of technology in education and to avoid adverse results in the long term. If technology is properly used, it will possibly reduce teacher workload and improve student outcomes in school. In the future, even after a person graduates from his school, proper blended learning mode may bring a person lifelong benefits.

\section{Reference}

[1] J. S. Zboun and M. Farrah, "Students' Perspectives of Online Language Learning during Pandemic: Benefits and Challenges," Indonesian EFL Journal, VII (1), pp. 13-20, Jan 2021.

[2] L. Choi and S. Chung, "Navigating Online Language Teaching in Uncertain Times: Challenges and Strategies of EFL Educators in Creating a Sustainable Technology-Mediated Language Learning Environment," mdpi.com, XXIII(14), para. 1, Jul. 9, 2021. [Online]. Available: https://www.mdpi.com/2071-1050/13/14/7664. [Accessed: Dec. 19, 2021].

[3] L. Mishra, T. Gupa and A. Shree, "Online Teaching-learning in Higher Education during Lockdown Period of COVID-19 Pandemic," International Journal of Educational Research Open, I (1), para. 3, Sept. 10, 2020. [Online].

Available: https://www.sciencedirect.com/science/article/pii/S26663740 20300121. [Accessed: Dec. 20, 2021].

[4] K. Ratheeswari, "Information Communication Technology in Education," Journal of Applied and Advanced Research, III(Suppl. 1), pp. 45-47, 2018.

[5] M. R. Ahmadi, "The Use of Technology in English Language Learning: A Literature Review," International Journal of Research in English, III(2), pp. 116-125, 2018.

[6] H. J. Becker, "Findings from the Teaching, Learning, and Computing Survey: Is Larry Cuban Right? ," Education Plicy Analysis Archives, VIII(51), Nov. 15, 2000. [Online]. Available:

https://epaa.asu.edu/ojs/index.php/epaa/article/view/442/565 [Accessed: Dec. 18, 2021].

[7] R. Raja and P. C. Nagasubramani, "Impact of Modern Technology in Education," Journal of Applied and Advanced Research, III(Suppl. 1), pp. 33-35, 2018.
[8] Y. Zhao, "Recent Development in Technology and Language : A Literature Review and Meta-analysis," CALICO Journal, XXI(1), pp. 7-27, 2003.

[9] C. Patel, "Use of Multimedia Technology in Teaching and Learning Communication Skill: An Analysis," International Journal of Advancement in Research \& Technology, II(7), pp. 116-123, 2013.

[10] K. Scalise, "Differentiated E-learning: Five Approaches through Instructional Technology," International Journal of Learning Technology, III(2) , pp. 169-182, 2007.

[11] C. A. Chapelle, "Focus on Learners," in English Language Learning and Technology, B. Harley and J. H. Hulstijin (eds.), John Benjamins Publishing Company, Philadelphia, 2003.

[12] S. Dhawan, "Online Learning: A Panacea in the Time of COVID-19 Crisis," Journal of Educational Technology, IL(1), pp. 5-22, 2020.

[13] M. M. Zalat, M. S. Hamed and S. A. Bolbol, "The Experiences, Challenges, and Acceptance of E-learning as a Tool for Teaching during the COVID-19 Pandemic among University Medical Staff," doi.org, Mar. 26, 2021. [Online]. Available: https://doi.org/10.1371/journal.pone.0248758. [Accessed: Sept. 28, 2021].

[14] D. Zondiros, "Online, Distance and Globalisation: Its Impact on Educational Access, Inequality and Exclusion," old.eurodl.org, 2008. [Online]. Available: https://old.eurodl.org/?p=special\&sp=articles\&inum=1\&artic le=302. [Accessed: Dec. 20, 2021].

[15] L. Song, E. S. Singleton, J. R. Hill and M. H. Koh, "Improving Online Learning: Student Perceptions of Useful and Challenging Characteristics," The Internet and Higher Education, VII(1), pp. 59-70, 2004.

[16] B. H. See, S. Gorard, B. Lu, L. Dong and N. Siddiqui, "Is Technology Always Helpful?: A Critical Review of the Impact on Learning Outcomes of Education Technology in Supporting Formative Assessment in Schools," Research Papers in Education, tandfonline.com, Mar. 29, 2021. [Online].

Available: https://www.tandfonline.com/doi/full/10.1080/02671522.202 1.1907778. [Accessed: Dec. 20, 2021].

[17] L. L. Shrum and E. W. Glisan, "Classroom Instruction and Oral Proficiency Levels," in Teacher's Handbook, L. L. Shrum and E. W. Glisan (eds.), Boston, Massachusetts, 2015. [18] P. K. Wilke, W. H. Gmelch and N. P. Lovrich, "Stress and Productivity Evidence of the Inverted U Function," Taylor \& Francis, Ltd, IX(4), pp. 342-356, 1985.

[19] S. E. Davis, "Learning Styles and Memory," Institute for Learning Styles Journal, I, pp. 46-51, 2007.

[20] F. Genesee, "Second Language Learning through Immersion: A Review of U.S. Programs," Sage Journal, LV(4),pp. 541-561, 1985.

[21] L. S. Vygotsky, Mind in society: The Development of Higher Psychological Processes, Harvard University Press, Cambridge, MA, 1978.

[22] H. Adam and A. D.Galinsky, "Enclothed Cognition," Science Direct, XLVIII(4), pp. 918-925, 2012.

[23] G. Stockwell, "Living and Learning with Technology: Language Learning with Mobile Devices," English Teaching, LXXVI(Suppl. 1), pp. 3-16, 2021. 


\section{References}

[1] J. S. Zboun and M. Farrah, "Students' Perspectives of Online Language Learning during Pandemic: Benefits and Challenges," Indonesian EFL Journal, VII (1), pp. 13-20, Jan 2021.

[2] L. Choi and S. Chung, "Navigating Online Language Teaching in Uncertain Times: Challenges and Strategies of EFL Educators in Creating a Sustainable Technology-Mediated Language Learning Environment," mdpi.com, XXIII(14), para. 1, Jul. 9, 2021. [Online]. Available: https://www.mdpi.com/2071-1050/13/14/7664.

[Accessed: Dec. 19, 2021].

[3] L. Mishra, T. Gupa and A. Shree, "Online Teaching-learning in Higher Education during Lockdown Period of COVID-19 Pandemic," International Journal of Educational Research Open, I (1), para. 3, Sept. 10, 2020. [Online]. Available: https://www.sciencedirect.com/science/article/pii/S266 6374020300121. [Accessed: Dec. 20, 2021].

[4] K. Ratheeswari, "Information Communication Technology in Education," Journal of Applied and Advanced Research, III(Suppl. 1), pp. 45-47, 2018.

[5] M. R. Ahmadi, "The Use of Technology in English Language Learning: A Literature Review," International Journal of Research in English, III(2), pp. 116-125, 2018.

[6] H. J. Becker, "Findings from the Teaching, Learning, and Computing Survey: Is Larry Cuban Right?," Education Plicy Analysis Archives, VIII(51), Nov. 15, 2000. [Online]. Available: https://epaa.asu.edu/ojs/index.php/epaa/article/view/442 /565 [Accessed: Dec. 18, 2021].

[7] R. Raja and P. C. Nagasubramani, "Impact of Modern Technology in Education," Journal of Applied and Advanced Research, III(Suppl. 1), pp. 33-35, 2018.

[8] Y. Zhao, "Recent Development in Technology and Language: A Literature Review and Meta-analysis," CALICO Journal, XXI(1), pp. 7-27, 2003.

[9] C. Patel, "Use of Multimedia Technology in Teaching and Learning Communication Skill: An Analysis," International Journal of Advancement in Research \& Technology, II(7), pp. 116-123, 2013.

[10] K. Scalise, "Differentiated E-learning: Five Approaches through Instructional Technology," International Journal of Learning Technology, III(2), pp. 169-182, 2007.

[11] C. A. Chapelle, "Focus on Learners," in English Language Learning and Technology, B. Harley and J. H. Hulstijin (eds.), John Benjamins Publishing Company, Philadelphia, 2003.

[12] S. Dhawan, "Online Learning: A Panacea in the Time of COVID-19 Crisis," Journal of Educational Technology, IL(1), pp. 5-22, 2020.

[13] M. M. Zalat, M. S. Hamed and S. A. Bolbol, "The Experiences, Challenges, and Acceptance of E-learning as a Tool for Teaching during the COVID-19 Pandemic among University Medical Staff," doi.org, Mar. 26, 2021. [Online]. Available: https://doi.org/10.1371/journal.pone.0248758.

[Accessed: Sept. 28, 2021].
[14] D. Zondiros, “Online, Distance and Globalisation: Its Impact on Educational Access, Inequality and Exclusion," old.eurodl.org, 2008. [Online]. Available: https://old.eurodl.org/?p=special\&sp=articles\&inum $=1$ \&article $=302$. [Accessed: Dec. 20, 2021].

[15] L. Song, E. S. Singleton, J. R. Hill and M. H. Koh, "Improving Online Learning: Student Perceptions of Useful and Challenging Characteristics," The Internet and Higher Education, VII(1), pp. 59-70, 2004.

[16] B. H. See, S. Gorard, B. Lu, L. Dong and N. Siddiqui, "Is Technology Always Helpful?: A Critical Review of the Impact on Learning Outcomes of Education Technology in Supporting Formative Assessment in Schools," Research Papers in Education, tandfonline.com, Mar. 29, 2021. [Online]. Available: https://www.tandfonline.com/doi/full/10.1080/0267152 2.2021.1907778. [Accessed: Dec. 20, 2021].

[17] L. L. Shrum and E. W. Glisan, "Classroom Instruction and Oral Proficiency Levels," in Teacher's Handbook, L. L. Shrum and E. W. Glisan (eds.), Boston, Massachusetts, 2015.

[18] P. K. Wilke, W. H. Gmelch and N. P. Lovrich, "Stress and Productivity Evidence of the Inverted U Function," Taylor \& Francis, Ltd, IX(4), pp. 342-356, 1985.

[19] S. E. Davis, "Learning Styles and Memory," Institute for Learning Styles Journal, I, pp. 46-51, 2007.

[20] F. Genesee, "Second Language Learning through Immersion: A Review of U.S. Programs," Sage Journal, LV(4), pp. 541-561, 1985.

[21] L. S. Vygotsky, Mind in society: The Development of Higher Psychological Processes, Harvard University Press, Cambridge, MA, 1978.

[22] H. Adam and A. D. Galinsky, "Enclothed Cognition," Science Direct, XLVIII(4), pp. 918-925, 2012.

[23] G. Stockwell, "Living and Learning with Technology: Language Learning with Mobile Devices," English Teaching, LXXVI(Suppl. 1), pp. 3-16, 2021. 